\title{
NUEVOS REGISTROS DE POZONIA ANDUJARI (ARANEAE: ARANEIDAE) PARA LA REPÚBLICA DOMINICANA
}

Giraldo Alayón García ${ }^{1}$, Gabriel de los $\operatorname{Santos}^{2}$ y Solanlly Carrero Jiménez ${ }^{2}$

'Museo Nacional de Historia Natural, La Habana, Cuba, moffly@infomed.sld.cu ${ }^{2}$ Museo Nacional de Historia Natural de Santo Domingo (MNHNSD).Calle César Nicolás Penson, Plaza de la Cultura, Santo Domingo, República Dominicana.

g.delossantos@museohistorianatural.gov.do, s.carrero@museohistorianatural.gov.do

\section{RESUMEN}

Se registran tres nuevas localidades para la araña Pozonia andujari Alayón, 2007.

Palabras clave: arañas, Pozonia, República Dominicana.

\section{ABSTRACT}

Three new localities are reported for the spider Pozonia andujari Alayón, 2007.

Key words: spiders, Pozonia, Dominican Republic.

El género Pozonia Schenkel, 1953 fue revisado por Levi (1993), con la inclusión de tres especies: P. bacillifera (Simon, 1897) de América del Sur, con registros en Trinidad; $P$. dromedaria (O.P.-Cambridge, 1893) de América Central y México; y P. nigroventris (Bryant, 1936), la de más amplia distribución, de América Central, México (Península de Yucatán), Cuba y Jamaica. Posteriormente, Alayón (2007) describe una especie para La Hispaniola (República Dominicana: El Matadero, Honduras, Baní, provincia Peravia), basada en una hembra. Según Levi (1993), estas arañas son escasas en las colecciones y rara vez colectadas u observadas en la naturaleza (las hembras adultas, ya que sólo se conoce el macho de $P$. nigroventris); es poco lo que se conoce sobre su variación, hábitos y requerimientos ecológicos. Por ello resulta interesante registrar la presencia de cualesquiera de las especies del género, más significativo en el caso de $P$. andujari, que se conocía de un ejemplar.

Se registran tres nuevas localidades, dos en la Cordillera Central y otra en la Región Este (fig. 2). Todos los ejemplares están depositados en el Museo Nacional de Historia Natural de Santo Domingo.

1) Una hembra adulta: Parque Nacional Juan Bautista Pérez Rancier, Valle Nuevo, Provincia San José de Ocoa; enero de 2010, Cols. R. Ortiz y M. Landestoy. Este ejemplar presenta 14 tubérculos en el opistosoma y los tarsos de los palpos y las patas I y II son oscuros. (fig. 1).

2) Una hembra juvenil (en el penúltimo estadio): Prov. San Juan, Sabaneta, Alto de la Rosa, cerca de la torre de observación, Parque Nacional José del Carmen Ramírez. $19^{\circ} 02^{\prime} 21.0^{\prime \prime} \mathrm{N} 071^{\circ} 13^{\prime} 20^{\prime \prime} \mathrm{W}$. 22-23 de noviembre de 2009, Cols. G. de los Santos y R. Ortiz.

3) Una hembra juvenil: Prov. La Altagracia, San Rafael del Yuma, Guaraguao, camino a las cavernas, Parque Nacional del Este, 6 de mayo de 1988, Col. J. Infante. 


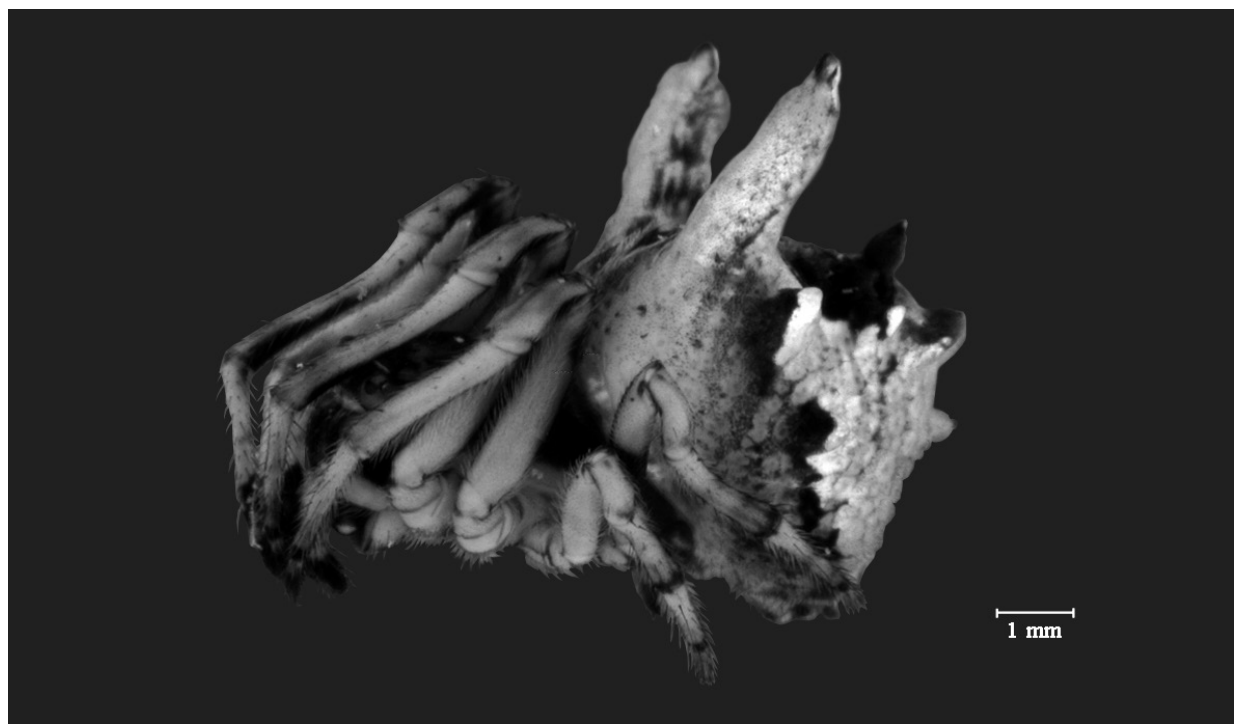

Figura 1. Vista lateral de Pozonia andujari Alayón.

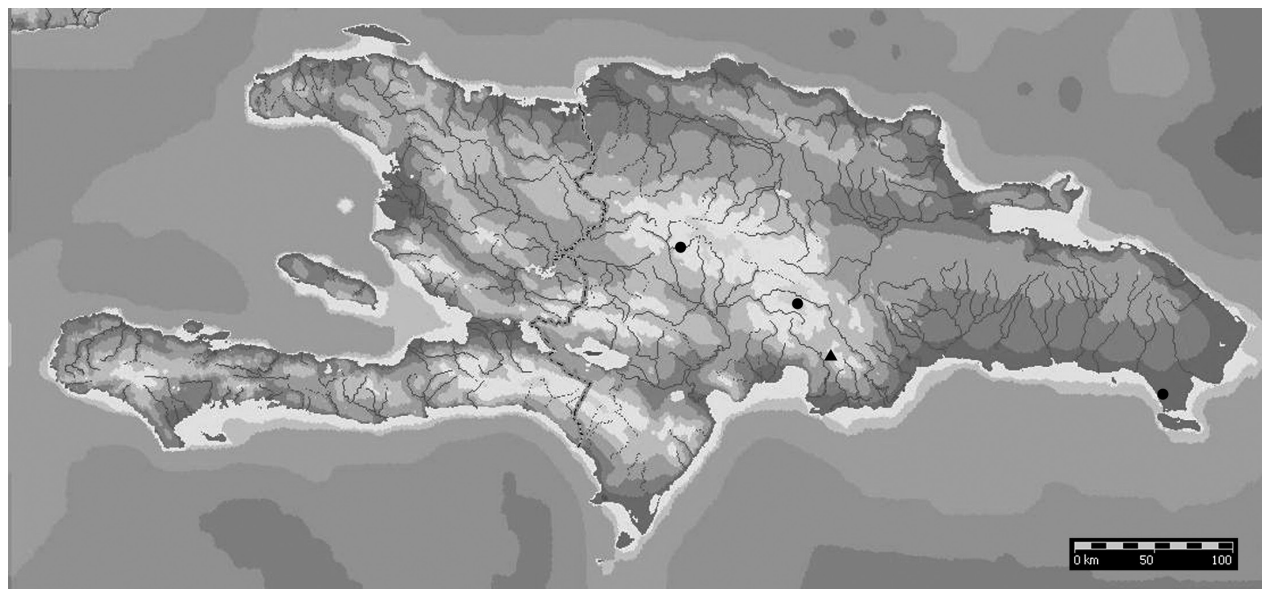

Figura 2. Localidades conocidas en la República Dominicana para Pozonia andujari Alayón. •, nuevos registros; $\mathbf{\Delta}$, localidad tipo.

\section{AGRADECIMIENTOS}

A la dirección del Museo Nacional de Historia Natural de Santo Domingo, por las facilidades brindadas en el examen de las colecciones de la institución y a la dirección del Instituto de Investigaciones Botánicas y Zoológicas de la Universidad Autónoma de Santo Domingo, por permitirnos hacer uso de sus equipos de fotografía.

\section{LITERATURA CITADA}

Alayón García, G. 2007. Especie nueva de Pozonia (Araneae:Araneidae) para República Dominicana. Solenodon, 6: 41-44.

Levi, H. W. 1993. The Neotropical Orb-Weaving Spiders of the Genera Wixia, Pozonia and Ocrepeira (Araneae: Araneidae). Bulletin of the Museum of Comparative Zoology, 153 (2): 47-141. 